\title{
Tradução antropofágica, circulação de clássicos e história da geografia brasileira contada por seus geotradutores
}

\author{
Entrevista com Leonardo Arantes e Rogério Haesbaert
}

Anthropofagical translation, circulation of classics and history of Brazilian geography narrated by their geotranslators. Interview with Leonardo Arantes and Rogério Haesbaert

Traduction anthropofagique, circulation des classiques et l'histoire de la géographie brésilienne racontée par ses géotraducteurs. Entretien avec Leonardo Arantes et Rogério Haesbaert

Traducción antropofágica, circulación de clásicos y la historia de la geografía brasileña contada por sus geotraductores. Entrevista a Leonardo Arantes y Rogério Haesbaert

\section{Guilherme Ribeiro e Marcos Vinícius Fernandes Gonçalves}

\section{(2) OpenEdition}

Journals

\section{Edição electrónica}

URL: https://journals.openedition.org/terrabrasilis/8099

DOI: 10.4000/terrabrasilis.8099

ISSN: 2316-7793

\section{Editora}

Rede Brasileira de História da Geografia e Geografia Histórica

\section{Refêrencia eletrónica}

Guilherme Ribeiro e Marcos Vinícius Fernandes Gonçalves, «Tradução antropofágica, circulação de clássicos e história da geografia brasileira contada por seus geotradutores», Terra Brasilis [Online], 15 | 2021, posto online no dia 31 julho 2021, consultado o 05 dezembro 2022. URL: http:// journals.openedition.org/terrabrasilis/8099; DOI: https://doi.org/10.4000/terrabrasilis.8099

Este documento foi criado de forma automática no dia 5 dezembro 2022.

All rights reserved 


\title{
Tradução antropofágica, circulação de clássicos e história da geografia brasileira contada por seus geotradutores
}

\author{
Entrevista com Leonardo Arantes e Rogério Haesbaert \\ Anthropofagical translation, circulation of classics and history of Brazilian \\ geography narrated by their geotranslators. Interview with Leonardo Arantes \\ and Rogério Haesbaert \\ Traduction anthropofagique, circulation des classiques et l'histoire de la \\ géographie brésilienne racontée par ses géotraducteurs. Entretien avec Leonardo \\ Arantes et Rogério Haesbaert \\ Traducción antropofágica, circulación de clásicos y la historia de la geografía \\ brasileña contada por sus geotraductores. Entrevista a Leonardo Arantes y \\ Rogério Haesbaert
}

Guilherme Ribeiro e Marcos Vinícius Fernandes Gonçalves

1 1. Em nossa investigação sobre a revista Geographia (UFF), vocês aparecem como os dois principais tradutores tanto na seção "Artigos" quanto na "Nossos Clássicos", com destaque para a presença de geógrafos alemães em língua portuguesa, os quais foram sufocados pela tradição francófona da geografia brasileira. Quais as motivações que os impeliram a trabalhar com tradução e qual o papel desse métier em suas trajetórias intelectuais?

LA: Caros Guilherme e Marcos Vinícius

3 Em primeiro lugar, gostaria de agradecer-lhes a oportunidade de pensar sobre uma das atividades pelas quais mais tenho prazer. Mais que isso, por me permitirem refletir sobre minha trajetória, estímulos e meios através dos quais descobri essa atividade, que é a minha grande paixão. Nesse sentido, essa também é uma excelente oportunidade para reconhecer e agradecer 
ao Prof. Rogério Haesbaert que, ao lado de meu orientador de mestrado e doutorado, o Prof. Ruy Moreira, foram os grandes incentivadores desse trabalho.

4 Falarei, então, de uma série de acasos, desses que acontecem frequentemente em nossas vidas $e$ que acabam por determiná-las. Faço eco aqui a uma passagem de Alexander von Humboldt em um texto autobiográfico por mim traduzido e publicado na GEOgraphia (Humboldt, 2016), no qual ele destaca acontecimentos aparentemente sem qualquer importância, mesmo insignificantes, mas que acabaram exercendo enorme impacto em sua vida, direcionando seus rumos. Mencionarei, portanto, os contatos com Valéria Trevizani Burla de Aguiar, Immanuel Kant, Guimarães Rosa, Maria Lucia Pires Menezes, Ruy Moreira, Rogério Haesbaert e a língua alemã até chegar à tradução.

5 Suas origens remontam ao meu primeiro período de graduação na UFJF, quando da realização da disciplina de "Introdução à Geografia" ministrada por aquela que viria a se tornar a minha primeira orientadora, discípula de Lívia de Oliveira e amante da Cartografia, a professora Valéria Trevizani Burla de Aguiar. À época, Valéria era Pró-Reitora Adjunta de Graduação e dividia seu tempo entre as atividades docentes e de gestão universitária. Em razão de um desses compromissos burocrático, Valéria necessitou se ausentar de uma de nossas aulas, solicitando ao seu filho mais velho, Gustavo, concluinte de Filosofia e Comunicação Social, que ministrasse uma aula para nossa turma. O tema foi a filosofia transcendental de Immanuel Kant situando sua importância no âmbito do pensamento ocidental moderno. Sua exposição contrastava em minha cabeça com as escassas e sempre breves e simplórias menções nos manuais introdutórios de Geografia Geografia (Sodré, 1976; Moraes, 1983; Andrade, 2006 [1987]) que à época liamos sobre as preleções de physische Geographie ministradas por Kant na universidade da então cidade de Königsberg.

6 Mas o tempo passou e cerca de um ano e meio mais tarde, em 2003, aquele acontecimento teria caído no esquecimento não fosse a vinda de um grupo de professores e estudantes alemães de Geografia provenientes da Universidade de Passau, Alemanha, que, em excursão pelo Brasil, realizou um dos trabalhos de campo na UFJF como parte de um convênio de intercâmbio recémfirmado entre as duas instituições.

7 Anos mais tarde, tomei conhecimento, salvo engano, através da colega e atual professora do Departamento de Geografia do Instituto Multidisciplinar da UFRRJ, Sarah Lawall, de que o então professor de Anthropogeographie que organizara aquele trabalho de campo, o Dr. Ernst Struck, havia solicitado a seleção de um aluno do curso de Geografia da UFJF para participar do intercâmbio no ano seguinte e que a própria Sarah concorreria à bolsa não fosse uma questão de ordem pessoal que inviabilizara sua ida.

8 Avisado então pela amiga de graduação Marina Furtado (atualmente professora do Departamento de Educação da UFJF) sobre o processo seletivo para graduandos da UFJF que desejassem concorrer a uma bolsa de estudos no âmbito daquele convênio, resolvi candidatar-me $e$ acabei sendo um dos quatro discentes contemplados - inicialmente, para um semestre e, depois, estendida por mais um, para o ano de 2004. Nesse momento começa, por assim dizer, a minha relação com a Alemanha, com a língua, a cultura e a Geografia alemãs. Um curso de língua alemã introdutório feito às pressas com um alemão que atuava, salvo engano, como intérprete na fábrica da Mercedes-Benz de Juiz de Fora, o professor Stephan, usando livro didático de uma renomada editora alemã, muito conhecida por seus dicionários, a Langenscheidt, serviu-me de guia inicial. Assim, aos 21 anos de idade, ainda muito imaturo, mas com uma vontade enorme de aprender e conhecer o mundo, partia eu para o Velho Mundo. Levo na bagagem, além de roupas e o Langenscheidt, aquela pesada indagação: o que aquele grande filósofo teria que ver de fato com a Geografia? 
9 Aqueles dez meses que compreenderam o semestre de inverno de 2004-2005 e o de verão em 2005 mudaram por definitivo os rumos da minha trajetória. Na bagagem de volta, dentre as muitas obras impressas e aquelas por mim digitalizadas, ${ }^{1}$ o volume IX das "Werke" de Kant, que compreendia as notas de suas preleções de Lógica, Pedagogia e Physische Geographie (Kant, 1923); na cabeça, um projeto de mestrado que contemplasse aquela questão que de certo modo me acompanhara desde o primeiro período da graduação.

10 Meu retorno é marcado por mais dois acontecimentos que viriam a conferir uma nova direção à minha carreira. O primeiro deles é a aproximação com a minha segunda orientadora, a professora Maria Lúcia Pires Meneses - discípula de Bertha Becker. Além de apresentar-me importantes aportes teórico-metodológicos em Geografia Urbana e Regional, é Maria Lúcia quem, através de seu saudoso marido - e, também, um dos meus maiores mestres na UFF -, me põe em contato com Ruy Moreira (cuja grandeza e relevância eu ainda de fato desconhecia) a fim de que este me orientasse em meu projeto de mestrado a respeito da Geografia de Kant.

11 Antes disso, contudo, um segundo acontecimento também aparentemente sem grande significância exerceu impacto considerável sobre meu percurso, a saber, a participação no Projeto Rondon - operação Minas Gerais, realizado sobretudo na cidade do Serro-MG, em cuja vereda nasce o Rio Jequitinhonha, e que me conduziu ao Ser-Tão de Rosa. Com Guimarães, um mundo de afinidades. A maior de todas, a paixão pela língua alemã.

12 Dessa viagem, volto então com o projeto de monografia na cabeça, uma análise do "Grande Sertão de Rosa para o Ensino de Geografia". E, no processo de levantamento bibliográfico, o encontro com a obra que me marcaria profundamente: "João Guimarães Rosa: correspondência com seu tradutor alemão Curt Meyer-Clason", publicada pela primeira vez dois ou três anos antes daquela viagem através de uma parceria entre a editora Nova Fronteira, a Editora da UFMG e a Academia Brasileira de Letras (Guimarães Rosa, 2003).

13 Foi nas epístolas de ambos que o aforismo italiano traduttore, traditore ganhou em minha mente clareza cristalina. Mas também foi ali, naqueles geniais diálogos e nas buscas por soluções de tradução, onde reconheci não apenas a importância da tradução e do papel do tradutor, mas também da relação indissociável entre práticas espaciais, representações do espaço e espaços de representação (para usarmos termos lefebvrianos [Lefebvre, 1974]), sendo a própria língua catalizadora dessas três esferas.

14 Defendida a monografia, lanço-me na busca por uma vaga no mestrado com aquele projeto sobre Kant. Uma vez que a greve da universidade havia empurrado minha formatura para o início de 2006, minha primeira tentativa é em meados deste mesmo ano na USP, e o nome do professor Dieter Heidemann - orientador de doutorado do Rogério - surge para mim como uma boa possibilidade tanto por sua ascendência germânica quanto por sua relação com Guimarães Rosa. À época de minhas investigações para a monografia de graduação, era ele quem estava à frente do Instituto de Estudos Brasileiros (IEB) - cujo acervo contém as cadernetas de campo de Guimarães Rosa -, e sua esposa também estava envolvida em pesquisas relacionadas ao escritor mineiro. Destarte, apesar da aprovação na primeira etapa do processo seletivo - que consistia em prova de língua estrangeira, sendo eu o único dos cerca de cento e vinte inscritos a eleger a língua alemã e, não por acaso, o próprio professor Dieter (minha indicação de orientador) era o responsável pela correção da prova de proficiência -, aquela primeira tentativa acabou malograda.

15 Assim, o ingresso para o mestrado será em outra universidade, a Federal Fluminense, em março de 2007, após breve experiência docente em um CIEP municipalizado na minha cidade natal de Volta Redonda-RJ. Aliás, ao lado de Guimarães Rosa, da tradição filosófica alemã, do marxismo, 
de Rosa Luxemburgo e da geografia alemã, Volta Redonda é mais uma das inúmeras afinidades e pontos de contato que eu desconhecia existir entre mim e meu novo orientador, o professor Ruy Moreira.

16 Ruy tem, sem dúvida, papel importantíssimo porque, mais que qualquer outro, reconhecia o papel seminal exercido pela geografia alemã e seu infeliz apagamento do pensamento geográfico brasileiro em razão do peso e da preponderância sobretudo dos mestres franceses, mas também da geografia norte-americana. Daí seu apoio no sentido de que eu avançasse não apenas no retorno ao pensamento geográfico alemão, mas também em sua revisão e sobretudo em seu resgate, a tradução cumprindo, nesse sentido, papel de relevo nesses três níveis de análise.

Ao lado de Ruy, foi sem dúvida o professor Rogério Haesbaert o maior responsável por minha inserção no âmbito da tradução, não apenas por ter me aberto as portas da GEOgraphia para a sua publicação e divulgação, mas por ter sido um entusiasta do trabalho de tradução e por ter se colocado à disposição para revisá-lo e comentá-lo, trazendo aspectos e debates por mim ignorados e sugerindo soluções cruciais e criativas tais como as que Guimarães Rosa propunha ao seu tradutor. Sem o incentivo e os estímulos do Rogério minhas traduções não teriam existido.

RH: Creio que antes da motivação pelas traduções tenho de falar da motivação por aprender línguas estrangeiras, pelo estreito vínculo entre as duas. Como a língua está diretamente ligada ao "espírito de um povo" e certamente é um dos elementos mais marcantes e singulares de uma cultura, aprender outros idiomas deveria ser um dos requisitos básicos para quem quer ser geógrafo. No meu caso, desde muito pequeno a paixão por conhecer outras culturas, outras geografias, caminhou junto com o interesse por outros idiomas. Minha mãe escutava diariamente rádios platinas, gostava de tango. Desde cedo fui me acostumando com expressões da língua espanhola. Infelizmente sua descendência alemã não teve o mesmo efeito, pois meu avô ensinou muito pouco alemão para os filhos principalmente depois das perseguições nas áreas de colonização alemã do Sul do Brasil durante a Segunda Guerra.

Vivendo próximo à fronteira com o Uruguai e a Argentina, com nove anos de idade tive minha primeira correspondente em espanhol: uma jovem de Buenos Aires que trabalhava numa agência de turismo e que eu encontrei no ônibus Porto Alegre-Buenos Aires quando eu vendia revistas na estação rodoviária de São Vicente do Sul (então General Vargas). Aos doze, já em Santa Maria, escrevi a uma chilena de Valparaíso que colocou anúncio no diário Folha da Manhã de Porto Alegre (somente há dois anos, "redescobertos" via Facebook, nos conhecemos pessoalmente). Tentava escrever em espanhol e ela me corrigia. Foi assim que aprendi espanhol sem nunca tê-lo estudado formalmente. Por sua vez, meu interesse pelo francês veio com o "ginásio". Nos anos 1960, era ainda a primeira (e única) língua estrangeira ensinada em cidades pequenas do interior do Rio Grande do Sul. Ao mudar para Santa Maria sofri muito, pois na escola em que estudei já estavam no $3^{\circ}$ ano de inglês. Durante o "Científico" (atual Ensino Médio), com o ensino profissionalizante obrigatório (programa da ditadura militar), minha opção foi por "Tradutor $e$ intérprete/Inglês". o primeiro texto que traduzi, um conto de Edgar Alan Poe, foi nesse curso uma condição para ser aprovado. Os muitos "correspondentes" que mantive, depois de colocar anúncio em uma revista do Rio de Janeiro, de países como Chile, México, Canadá e Alemanha (escrevendo em inglês) me ajudaram a manter o conhecimento básico em espanhol e inglês.

0 sonho de uma bolsa de estudos no exterior era antigo. Imaginando uma na Alemanha, cursei um ano de alemão no Instituto Goethe de Santa Maria - alemão que depois, para minha grande frustração, foi totalmente esquecido. Além dos livros que eu lia em espanhol (como as traduções de Lefebvre De lo Rural al Urbano e El Derecho a la Ciudad [Lefebvre, 1978, 1978a]), o inglês acabou se firmando como a língua estrangeira por excelência, e com ela enfrentei muito bem a prova para o mestrado na UFRJ. Já no primeiro ano do curso em 1982, sob orientação da 
professora Bertha Becker e a seu convite, juntamente com a colega Carmen Silveira organizamos um seminário internacional vinculado à UGI do qual resultou o livro Abordagens Políticas da Espacialidade (Becker, Haesbaert e Silveira, 1983), no qual traduzimos do inglês e do espanhol textos de grandes nomes da Geografia da época participantes do evento como Edward Soja, Arie Shachar, Walter Stôhr e Miguel Morales. Foi meu primeiro grande exercício de tradução, o qual muito devo à orientadora Bertha Becker, além do auxilio de outros geógrafos como Lia Osório Machado.

21 A língua francesa retornaria com força para a realização do doutorado-sanduíche em Paris em 1992. Em segundo plano desde os estudos do ensino médio e com a perda de influência da geografia francesa, fui obrigado a realizar curso particular antes de viajar e, lá chegando, fui direto para a Aliança Francesa. A esse apressado aprendizado formal somou-se o cotidiano e as apresentações durante os seminários promovidos pelo meu supervisor Jacques Lévy. Enfim, o pós-doutorado me levaria, dez anos depois, à Inglaterra, consolidando o inglês como idioma básico da minha formação.

Motivação não faltou, portanto, para o aprendizado de línguas estrangeiras e, ocasionalmente, para traduções, ainda que a maioria informais. Elas só se consolidariam, de fato, com a criação da revista GEOgraphia, em 1999, de cujo comitê editorial participei até o ano passado (2020), permanecendo agora apenas como responsável justamente pela seção Nossos Clássicos (e também pela recém-criada seção Conceitos Fundamentais). Embora isso não corresponda a um projeto detalhado, construído previamente, as traduções acabaram se dando em duas frentes: artigos de abertura com autores estrangeiros reconhecidos que nos visitaram (caso, por exemplo, de Benno Werlen, Paul Claval, Jacques Lévy e Doreen Massey) e artigos da seção Nossos Clássicos.

A mobilização de outros colegas também foi fundamental seja na divisão de tarefas (caso de Sylvain Souchaud, com quem dividi traduções), seja em minha atuação apenas como revisor caso das traduções de Leonardo Arantes, responsável por algumas das mais importantes contribuições para a revista, cobrindo uma grande lacuna em relação às traduções em língua alemã. Algumas vezes recorremos também ao geógrafo teuto-brasileiro Wolf Dietrich Sahr (UFPR), responsável pela organização da vinda de Benno Werlen ao Brasil e revisor, além de clássicos alemães, da tradução de artigo por mim traduzido do inglês (Werlen, 2001).

A motivação desde o início foi traduzir textos inéditos em português de geógrafos clássicos que marcaram a história do pensamento geográfico, mas também abrindo espaço para a republicação de textos de autores clássicos em língua portuguesa. A preferência inicial dada a geógrafos como Paul Vidal de la Blache acabou nos estimulando a desdobrar projetos mais ousados, como o que, juntamente com a participação decisiva de Guilherme Ribeiro e Sergio Nunes, resultou na coletânea Vidal, Vidais. Textos de geografia humana, regional e política (Haesbaert, Nunes Pereira e Ribeiro, 2012), cobrindo uma lacuna na bibliografia disponível no Brasil sobre um de nossos maiores clássicos. É sob essa mesma motivação que sugerimos a Willian Morais Antunes de Sousa a tradução de "As ciências geográficas", de Camille Vallaux, ora em andamento e na qual pretendo atuar como revisor.

Para finalizar, sem dúvida uma das grandes motivações que nos levaram a desenvolver e/ou a estimular traduções na Geografia, para além dos "clássicos" (antigos), representando ademais um papel importante na nossa própria formação, foi o fortalecimento de vínculos com geógrafos contemporâneos. Daí traduções como a do projeto mais desafiador que assumimos: o livro Pelo Espaço, de Doreen Massey (Massey, 2008 [2005]), minha supervisora de pós-doutorado. Embora o resultado tenha ficado bem aquém do almejado, por força de dificuldades no domínio da linguagem (apesar de todo o auxilio da própria autora) e na relação com a tradutora, bióloga 
de formação (o que nos levou, no meio do percurso, a passar de revisor a segundo tradutor), foi uma contribuição relevante à renovação do pensamento espacial no contexto brasileiro.

2. A partir dos nossos levantamentos, constatamos que o Boletim Geográfico do IBGE publicou quase quatrocentos e cinquenta traduções de 1943 a 1978 de um total de dois mil e trezentos textos (18.81\%). Assim, não seria de se espantar que tal cifra faça dele o periódico ocidental de geografia que mais investiu nesse gênero. Entre 1999 e 2019 a Geographia (UFF) verteu sessenta artigos dentre quatrocentos e quarenta e um publicados (13,6\%). Tratar-se-ia de uma subordinação intelectual às línguas e às tradições hegemônicas (cf. Pascale Casanova em La langue mondiale. Traduction et domination [2015]), de uma abertura antropofágica ao exterior (cf. a herança modernista de Oswald de Andrade recuperada recentemente por Fernando Santoro e Luisa Buarque no Prefácio da edição brasileira do Dicionário dos intraduzíveis: um vocabulário das filosofias de Barbara Cassin [2018]) ou podemos explicar tal recorrência de outras maneiras?

LA: Penso que há um paradoxo insolúvel nesse sentido. A Ciência Geográfica moderna nasce como um projeto alemão, em primeiro lugar, tornando-se um projeto europeu e eurocêntrico na sequência. Por maior que seja o nosso empenho em descolonizar a Ciência Geográfica, continuamos praticando-a enquanto Ciência Geográfica, ou seja, enquanto um campo científico moderno recortado e moldado pelo pensamento eurocêntrico, e isso faz com que, queiramos ou não, nossa disciplina tenha uma dimensão eurocêntrica inerente, constitutiva. Isso não quer dizer que não possamos e, mais, que não devamos buscar geografias alternativas, contrahegemônicas, subversivas etc.. Pelo contrário. No entanto, precisamos estar cientes de que enquanto estivermos dentro desse enquadramento de pensamento estaremos, de algum modo, em algum nivel, atrelados a uma esfera de eurocentricidade. E se a isso agregarmos a ideia fundamental da indissociabilidade entre pensamento e linguagem reconheceremos ainda mais facilmente que estamos duplamente presos ao pensamento eurocêntrico: epistêmica e linguisticamente.

Contudo, o fato de termos sido colonizados e o fato dessa colonização ter sido, ainda que hegemonicamente organizada pelos portugueses, extremamente diversificada e plural, com a presença de empreendimentos coloniais italianos, alemães, japoneses, etc. consorciada a uma colonização da mentalidade da elite pela influência francesa, teve como consequência o nosso posicionamento numa esfera de confluência de formas distintas de pensar. De modo que aquilo que por um lado pode ser visto como subordinação intelectual, por outro pode ser encarado como um espaço mais aberto e mais receptivo de novas ideias, como uma espécie de "tradição de tradições" que bebe de várias fontes e residindo exatamente nisso sua riqueza, pluralidade e diversidade. Tendo a compreender esse processo mais a partir dessa segunda via, sem perder de vista a marca da colonialidade do saber de algum modo sempre presente.

RH: Leonardo já ressaltou bem o caráter colonial de nossa disciplina - no duplo sentido, aqui, de ter servido ao colonialismo (no caso, impondo-nos uma língua hegemônica), e de ter mantido forte subordinação ao pensamento euro-norte-americanocêntrico. Apenas gostaria de ressaltar que essa colonialidade do saber se dá em diversas escalas, e o Brasil também tem seu papel, com aquilo que nossos vizinhos de língua espanhola denominam, com exagero, "escola" geográfica crítica brasileira. Por sorte a proximidade entre nossas línguas não impõe de forma compulsória traduções do português para o espanhol, mas também aí percebemos uma via de (quase) mão única: são muito mais raras, na América Latina, traduções de geógrafos de língua espanhola para o português do que de geógrafos brasileiros para o espanhol.

Atendo-me à Geografia brasileira em relação ao "centro" europeu e norte-americano tenho alguma simpatia pelos processos de antropofagização que marcam nossa história cultural e que, 
creio, pelo menos em parte também se refletem na forma como assimilamos autores do "Norte" (vide nosso artigo "Hibridismo cultural, antropofagia identitária e transterritorialidade", traduzido também para o inglês [Haesbaert, 2011, 2012). Nesse sentido, lembro sempre meu convívio com geógrafos ingleses e o quanto Doreen Massey destacava o fato de dominarmos várias línguas. Ela, falando muito bem francês e espanhol e conseguindo ler em português, era uma raridade nos departamentos de Geografia da Inglaterra. Quando debati um trabalho na Open Universiy ela, na apresentação, fez questão de ressaltar (não sei se para que perdoassem minhas falhas no inglês...) que o inglês era "meu quarto idioma" (após português, espanhol e francês). Também falou que tinha influência de "várias escolas". E isso me lembrou outra vez nossa "capacidade antropofágica".

31 Em parte sob pressão da violência colonizadora, em parte como forma de resistência das culturas "originárias" à padronização moderno-colonial, essa espécie de aptidão para a mistura revelada pelo que Oswald de Andrade denominou de antropofagia (de Andrade, 2017 [1928]), em diferentes graus, ao lado de uma profunda colonialidade, também marca nossa relação intelectual com o "centro". E isso não só no âmbito do diálogo intradisciplinar - também no âmbito mais amplo das Ciências Sociais e da Filosofia. Se olharmos a obra de nosso maior geógrafo, por exemplo, quais são as grandes influências no pensamento de Milton Santos? Tudo bem que predomina a herança francesa, mas percebam o quanto há de intuição "tropical" (a partir do termo "flexibilidade tropical", que ele próprio cunhou [Santos 1991]) no seu discurso e em suas proposições conceituais. Tudo isso é de enorme complexidade, mas não podemos em hipótese alguma reduzir esses vínculos a uma relação subsidiária ou de subordinação. Até porque, como vimos, as escalas são múltiplas e nós também, assim como o Centro-Sul subordina o Norte-Nordeste, numa espécie de colonialismo intelectual interno, estamos também, em algum grau, subordinando outros pensamentos geográficos no contexto latino-americano.

3. Embora possamos afirmar que parte da história da geografia brasileira é indissociável do impacto exercido pelas traduções (dos franceses fundadores da USP e da Universidade do Brasil nos anos trinta até chegarmos aos livros mais recentes de David Harvey [para citar apenas dois exemplos]), nem por isso elas têm merecido a devida atenção como tema geográfico digno de estudos. Desnaturalizá-las e retirá-las de sua dimensão exclusivamente linguística parecem passos essenciais nesse sentido. Quais seriam as razões dessa negligência e como reverter tal quadro analisando-as na condição de objetos geográficos?

33 LA: Isso parece acontecer não apenas com a tradução, mas com a própria produção científica. Apenas recentemente o fenômeno da ciência parece ter se tornado tema de atenção dos geógrafos enquanto objeto geográfico passivel de ser compreendido a partir de sua espacialidade, isto é, cuja produção é considerada tanto à luz do seu local de produção e enunciação quanto dos processos de circulação, divulgação e difusão de seus produtos. Nesse sentido a contribuição do geógrafo britânico David Livingstone, Putting science in its place, parece ter dado impulso à investigação da ciência enquanto objeto geográfico (Livingstone 2003).

34 A mim me parece, contudo, que uma explicação possivel para a falta de interesse dos geógrafos brasileiros com os estudos relativos à espacialidade da tradução muito provavelmente esteja associada a um eventual baixo interesse pela própria tradução em si, não apenas em acessá-la, como também em produzi-la. E isso passa certamente pelo não reconhecimento de sua importância enquanto fonte indispensável para o entendimento epistemológico e historiográfico em seus mais distintos níveis, seja à luz da história do campo, da história institucional, da história conceitual e assim por diante. 
RH: Como bem destacou Leonardo, há pouco tempo que "o fenômeno da ciência" se tornou "objeto geográfico passível de ser entendido a partir de sua espacialidade". E eu acrescentaria, talvez não só na Geografia. Outras áreas começaram a perceber, apenas recentemente, a importância disso que pensadores descoloniais denominam "geopolítica do conhecimento", e que tem tudo a ver com o "regime geográfico" de traduções. Numa linguagem foucaultiana, poderíamos afirmar que até a tradução seria mais um dos "dispositivos de poder" que regem geograficamente nossos circuitos de conhecimento.

Além do "eventual baixo interesse pela própria tradução em si, não apenas em acessá-la, como também em produzi-la", vemos certa carência de bons tradutores na Geografia brasileira. Até porque, eu diria, por incrível que pareça, temos muitas vezes pouco domínio da própria língua portuguesa. Há muito geógrafo escrevendo mal... Sem falar no discurso pouco atraente em termos literários... mas não é preciso exigir tanto... Hoje em dia, dois fatores também jogam contra nosso esforço em boas traduções: o aprimoramento de sistemas digitais de tradução, como o Google Tradutor, que facilita (e às vezes engana) a vida de tanta gente, e o desprezo de nossos periódicos pelas traduções, consideradas cada vez menos relevantes nos próprios critérios de avaliação, que favorecem a publicação de textos no original, geralmente em inglês. Para completar, no caso da língua portuguesa, ainda temos a facilidade da leitura em espanhol, língua em que muitos livros de Geografia também são traduzidos.

4. Em termos prognósticos, a irrefreável expansão global da língua inglesa, a decadência visível do francês e as dificuldades intrínsecas ao aprendizado do alemão (sobretudo em um país periférico como o nosso) sugerem a manutenção da tradição tradutora nacional ou seu arrefecimento?

LA: Desde aproximadamente o início dos anos 2000, venho observando a paulatina transformação dos periódicos geográficos germânicos, até então tradicionalmente publicados exclusivamente em língua alemã em sua esmagadora maioria, e que a partir de então passaram a permitir textos em língua inglesa. Assim, rapidamente eles foram se tornando cada vez mais corriqueiros e predominantes a ponto de as revistas terem definido como política editorial a adoção do inglês como única língua de publicação.

39 Penso que essa tendência, embora apresentando-se em ritmo infinitamente mais lento em nossa realidade brasileira, deve pouco a pouco prevalecer nos periódicos geográficos mundo afora, e isso provavelmente é uma tendência para todos os campos do saber moderno. Esse processo certamente implica em enormes perdas. Sabemos que uma língua não se constitui como uma mera coleção de vocábulos. Ao contrário, expressa um modo de ser e de pensar, ou seja, porta consigo uma cultura. Sobretudo em se tratando de humanidades, as perdas são enormes. É nesse sentido que vejo a possibilidade de resistência. Mas a lógica das agências de fomento à pesquisa e a globalização crescente do fazer científico são molas propulsoras - no sentido da difusão do inglês como língua científica - muito difíceis de serem enfrentadas.

RH: Também concordo com Leonardo de que o inglês se firmará cada vez mais, especialmente por sua difusão como língua padrão via internet. Apenas para não ser tão pessimista, eu diria que a expansão do chamado pensamento pós-colonial - ou, especialmente entre nós, as abordagens descoloniais - tende a estimular uma pequena mudança, com um maior reconhecimento, no âmbito acadêmico, dos "idiomas do Sul". Isso é nítido entre alguns geógrafos ingleses, por exemplo, que têm promovido um diálogo de mão dupla, incentivando inclusive a tradução de trabalhos em português e espanhol para o inglês. Isso é bem evidente em um grupo do qual participo, o Latin American Geographies-UK, que reúne geógrafos latino-americanos $e$ anglófonos interessados nos estudos pós ou descoloniais na América Latina. Com a França esse tipo de relação é mais antiga, talvez até pela relativa perda de hegemonia da Geografia francesa 
desde pelo menos os anos 1970 - vide, por exemplo, Paul Claval e Jacques Lévy (em parte também Vincent Berdoulay) falando fluentemente português e, no caso de Claval, ele próprio, numa grande generosidade, traduzindo artigos do português para o francês.

41 5. A partir dos diferentes papéis de leitor, professor, pesquisador, editor de periódico e tradutor, como vocês interpretam os efeitos da seção "Nossos Clássicos" para a geografia brasileira?

42 LA: A iniciativa do professor Rogério na condução da revista GEOgraphia no que tange em espacial à seção "Nossos Clássicos" é louvável e precisa ser seguida pelos periódicos geográficos brasileiros. Recentemente criamos com o professor Dr. Eduardo Karol uma nova seção na revista Tamoios (Departamento de Geografia da Faculdade de Formação de Professores da UERJ) que visa precisamente contribuir para suprir essas lacunas, com traduções não apenas de textos consagrados na História do Pensamento Geográfico, mas também de reflexões contemporâneas que porventura venham enriquecer a Geografia brasileira.

43 Não apenas do ponto de vista da pesquisa, mas também do ensino essas traduções podem ser bastante úteis. A propósito, tenho ministrado o curso de HPG na FFP-UERJ a partir de inúmeras dessas traduções, as quais considero como verdadeiros textos programáticos, redigidos por pensadores com o claro objetivo de estabelecer as bases epistemológicas, teóricas e metodológicas do campo a fim de direcionar as práticas da comunidade de geógrafos em um dado contexto.

Porém, avaliar a repercussão da seção para a geografia brasileira não parece ser tarefa das mais fáceis. Uma análise quantitativa do número de acessos, comparado com o número de acessos a artigos de outras seções da própria revista (bem como de outros periódicos), poderia lançar luz sobre alguns aspectos relevantes. Melhor seria se essa análise quantitativa se desse consorciada com uma análise qualitativa, por exemplo, de sua menção em referências bibliográficas de dissertações de mestrado e apropriações concretas nas mesmas, tarefa certamente demasiado extensa.

De qualquer modo, jamais acreditei em um impacto imediato dessa produção; no entanto, penso que a longo prazo ela possa ganhar mentes e corações e se tornar cada vez mais significativa para a geografia brasileira. Vida longa à tradução!

RH: Como disse Leonardo, é difícil avaliar, mas tenho conhecimento, através de diálogos informais, de um uso frequente em alguns cursos (especialmente nas disciplinas História do Pensamento Geográfico e Teoria da Geografia) em diversas universidades brasileiras. Apesar de todos os entraves, deveríamos envidar todos os esforços para criar um circuito de traduções em todo o Brasil que diversificasse a origem linguística (apesar do amplo domínio, hoje, das geografias anglófonas). Ao lado da expansão de seções como a "Nossos Clássicos" em periódicos (como ocorre com a louvável iniciativa da revista Tamoios), uma ideia seria criar uma rede de potenciais tradutores e seus autores/obras/temáticas de interesse. Traduzir não é nada fácil, demanda conhecimento e paciência, e deveria ser um trabalho mais coletivo e planejado. Fica a ideia da criação da rede. Pessoalmente, num prazo amplo, creio que estarei comprometido - $e$ empolgado - com as "Ciências Geográficas" de Vallaux. Encerrando, aproveito para também agradecer a Guilherme pela iniciativa, que nos fez refletir sobre tradução, por vezes em perspectivas que até aqui não havíamos pensado. 


\section{BIBLIOGRAFIA}

Andrade, Manuel Correia de. Geografia: Ciência da sociedade. 2. ed. Recife: Editora da UFPE, 2006. 247p. [Primeira edição: Editora Atlas, 1987, 143p.].

Becker, Bertha; Haesbaert da Costa, Rogério; Silveira, Carmen (orgs.). Abordagens políticas da espacialidade. Rio de Janeiro: UFRJ/Departamento de Geografia, 1983. 175p.

Casanova, Pascale. La langue mondiale. Traduction et domination. Paris : Seuil 2015. 129p.

de Andrade, Oswald. Manifesto antropófago e outros textos. Penguin \& Companhia das Letras, 2017 [1928], p. 49-60.

Guimarães Rosa, João. Correspondência com seu tradutor alemão Curt Meyer-Clason (1958-1967). Organização de Maria Apparecida Faria Marcondes Bussolotti. Tradução de Erlon José Paschoal. Belo Horizonte: Editora UFMG; Rio de Janeiro: Editora Nova Fronteira/Academia Brasileira de Letras, 2003. 447p.

Haesbaert, Rogério; Nunes Pereira, Sergio; Ribeiro, Guilherme. Vidal Vidais: textos de geografia humana, regional e política. Rio de Janeiro: Bertrand Brasil, 2012. 464p.

Haesbaert, Rogério. Hibridismo Cultural, “antropofagia' identitária e transterritorialidade. In: Barthe-Deloizy, Francine; Serpa, Angelo (orgs.). Visões do Brasil: estudos culturais em Geografia. 1. ed. Salvador: EDUFBA e Edições L'Harmattan, 2012, p. 27-46.

Haesbaert, Rogério. Cultural Hybridism, Identitary Anthropophagy and Transterritoriality. In: Roca, Zoran; Claval, Paul; Agnew, John (ed.) Landscapes, Identities and Development. Farham and Burlington: Ashgate, 2011, p. 81-93.

Humboldt, Alexander von. Eu sobre mim mesmo (Meu percurso até me tornar naturalista e viajante-pesquisador [1769-1790]). GEOgraphia, n. 38, 2016, p.168-172. Traduzido do alemão por Leonardo Arantes.

Kant, Immanuel. Logik, Physische Geographie und Pädagogik. Gesammelten Schriften, (AK.9). Berlim: Walter de Gruyter, 1923. 572p.

Lefebvre, Henri. De lo rural a lo urbano. Antologia preparada por Mario Gaviria. Barcelona: Península, 1978a [1970]. Traducción de Javier González-Pueyo. 270p.

Lefebvre, Henri. El derecho a la ciudad. Barcelona: Península, 1978 [1968]. Traducción de Javier González-Pueyo. 176p.

Livingstone, David N. Putting science in its place. Geographies of scientific knowledge. Chicago and London: The University of Chicago Press, 2003. 244p.

Massey, Doreen. Pelo espaço. Uma nova política da espacialidade. Rio de Janeiro: Bertrand Brasil. Tradução de Hilda Pareto Maciel e Rogério Haesbaert, 2008 [2005]. 312p.

Moraes, Antonio Carlos Robert. Geografia: Pequena história crítica. 17. ed. São Paulo: Hucitec, 1999 [1983]. 138p.

Santoro, Fernando; Buarque, Luisa. Prefácio da edição brasileira. In: Cassin, Barbara. Dicionário dos intraduzíveis: um vocabulário das filosofias. Volume Um: Línguas. Organização de Fernando Santoro e Luisa Buarque. Belo Horizonte: Autêntica, 2018, p.5-15.

Santos, Milton. Técnica, espaço, tempo. Globalização e meio técnico-científico-informacional. São Paulo: Hucitec, 1994 [1991]. 174p. 
Sodré, Nelson Werneck. Introdução à Geografia: geografia e ideologia. Petrópolis: Vozes, 1976. 135p.

Werlen, Benno. Regionalismo e sociedade política. GEOgraphia, n. 4, 2001, p. 7-25. Tradução: Rogério Haesbaert. Revisão: Wolf-Dietrich Sahr.

\section{NOTAS}

1. Obras que eu havia adquirido quando da realização das disciplinas na universidade, desde as clássicas como a "Kritik der reinen Vernunft" (Crítica da razão pura) e a "Metaphysik der Sitten" (Metafísica dos costumes) de Kant e "Über Gewissheit" (Sobre a certeza) de Wittgenstein, passando por obras de filosofia da ciência como "Wider den Methodenzwang" (Contra o método) de Feyerabend, de sociologia como "Wirtschaft und Gesellschaft" (Economia e sociedade) de Weber e "Philosophische Kultur" (Cultura filosófica) de Simmel, até manuais acadêmicos no campo da Geografia como os trabalhos "Einführung in die Anthropogeographie/ Humangeographie" (Introdução à Antropogeografia/Geografia humana) e "Einführung in die Stadtgeographie" (Introdução à Geografia urbana) de Heinz Heineberg, bem como a versão alemã da "Physical Geography" dos Strahler. Desconhecendo o serviço lançado exatamente nesse mesmo período pela Google e hoje amplamente conhecido como Google Books, que passava a digitalizar e disponibilizar gratuitamente obras de domínio público e materiais sem direitos autorais, e admirado pelo fato da biblioteca universitária permitir que obras tão antigas e raras pudessem ser emprestadas e levadas para casa, adquiri um scanner de mesa a fim de digitalizalas, pois imaginava que dificilmente eu teria acesso a tais obras no Brasil. Foi assim que passei os dois últimos meses da minha estadia na Alemanha, digitalizando praticamente todos os clássicos da Geografia alemã, de Richthofen e Ratzel, passando por Penck, Hettner, Alfred Weber, von Thünen etc.

\section{RESUMOS}

Ao explorar as relações entre tradução, circulação assimétrica do conhecimento e história da geografia no Brasil mobilizada por alguns periódicos, a seção Nossos Clássicos da revista GEOgraphia (UFF) ocupa papel de destaque na conjuntura marcada pelo fim da hegemonia do IBGE e a subsequente propagação dos cursos de mestrado e doutorado a partir dos anos noventa do século vinte. Pela frequência de seus trabalhos como geotradutores, Leonardo Arantes e Rogério Haesbaert foram convidados a refletir sobre como suas trajetórias intelectuais têm sido atravessadas pelas traduções em um país periférico como o Brasil.

In exploring the relations between translation, the assymetrical circulation of knowledge, and the history of Brazilian geography mobilized in various journals, GEOgraphia's Our Classics occupies an important role in a context marked by the end of the IBGE's hegemony and the subsequent development of postgraduate courses in the 1990s. As important geotranslators in the journal, Leonardo Arantes and Rogério Haesbaert are invited here to consider how their own intellectual trajectories in a peripheral country like Brazil have been criss-crossed with translation. 
La section "Nos Classiques" publiée par GEOgraphia a eu un rôle important dans un contexte marqué par la fin de l'hégémonie de l'IBGE et le développement des cours de master et doctorat depuis les années 1990 au Brésil. Cette section articule les rapports entre traduction, circulation asymétrique de la connaissance et histoire de la géographie brésilienne. Grâce à leur fréquente participation en tant que géo-traducteurs, Leonardo Arantes et Rogério Haesbaert ont été invités à réfléchir sur la manière dont leurs trajectoires intellectuelles ont rencontré l'enjeu de la traduction dans un pays périphérique comme le Brésil.

Al explorar las relaciones entre la traducción, la circulación asimétrica del conocimiento y la historia de la geografía en Brasil movilizada por algunas revistas, la sección Nuestros Clásicos de la revista GEOgraphia (UFF) juega un papel destacado en la situación marcada por el fin de la hegemonía del IBGE y la posterior difusión de los cursos de maestría y doctorado a partir de los años noventa del siglo XX. Por la frecuencia de su trabajo como geotraductores, Leonardo Arantes y Rogério Haesbaert reflexionan sobre cómo sus trayectorias intelectuales han sido atravesadas por las traducciones en un país periférico como Brasil.

\section{ÍNDICE}

Índice geográfico: Brasil

Índice cronológico: Século XX, Século XXI

Palavras-chave: tradução, geotradutores, história da geografia brasileira, trajetória de geógrafos, geopolítica do conhecimento

Mots-clés: traduction, géo-traducteurs, histoire de la géographie brésilienne, trajectoire de géographes, géopolitique de la connaissance

Palabras claves: traducción, geotraductores, historia de la geografía brasileña, trayectoria de geógrafos, geopolítica del conocimiento

Keywords: translation, geotranslators, history of Brazilian geography, geographers' trajectory, geopolitics of knowledge

\section{AUTORES}

\section{GUILHERME RIBEIRO}

LAPEHGE/PPGGEO/UFRRJ. E-mail: lapehge@gmail.com

\section{MARCOS VINÍCIUS FERNANDES GONÇALVES}

Graduando em Geografia na UFRRJ, integrante do LAPEHGE e bolsista PIBIC-CNPq/UFRRJ entre 2017 e 2020 